\title{
Fine-Mapping of the PLCL2 Gene Identifies Candidate Variants Associated With Ischaemic Stroke Risk in Metabolic Syndrome Patients
}

\section{Xiaoya Huang}

Wenzhou Central Hospital

Qiang Ye

The Frist Affiliated Hospital of Wenzhou Medical University

\section{Yanlei Zhang}

The First Affiliated Hospital of Wenzhou Medical University

\section{Yanyan Chen}

The First Affiliated Hospital of Wenzhou Medical University

Jia Li

The First Affiliated Hospital of Wenzhou Medical University

Jun Sun

Wenzhou Central Hospital

zusen Ye ( $\nabla$ zusenye@163.com )

The First Affiliated Hospital of Wenzhou Medical University https://orcid.org/0000-0002-2627-534X

\section{Research Article}

Keywords: Ischaemic stroke, PLCL2 gene, Polymorphism, Metabolic syndrome, Prognosis

Posted Date: February 12th, 2021

DOl: https://doi.org/10.21203/rs.3.rs-189717/v1

License: (9) This work is licensed under a Creative Commons Attribution 4.0 International License. Read Full License

Version of Record: A version of this preprint was published at Frontiers in Neurology on January 20th, 2022. See the published version at https://doi.org/10.3389/fneur.2021.743169. 


\section{Abstract}

\section{Background and aims}

A genome-wide association study (GWAS) reported PLCL2 on chromosome 3p24.3 (rs4618210:A>G) as a novel susceptibility locus for myocardial infarction in the Japanese population. As the most common pathological process, atherosclerosis leads to metabolic syndrome (MetS)-related ischaemic stroke (IS) and myocardial infarction. Hypothesizing that polymorphisms of the PLCL2 gene might be associated with the onset and prognosis of IS in MetS patients, we performed the following study in a Chinese Han population.

\section{Methods}

A total of 709 cases (patients with MetS plus IS) and 711 controls (patients with MetS) were enrolled. A fine-mapping strategy was adopted to identify tagged single nucleotide polymorphisms (SNPs) of the PLCL2 gene, and improved multiplex ligation detection reaction (iMLDR) technology was used to genotype the selected SNPs. Logistic regression was used to analyse the values of the selected SNPs for the risk of IS between the cases and controls, adjusting for sex, age, hypertension, dyslipidaemia, hyperglycaemia, smoking and drinking. To compare the mean age of IS onset among different risk score groups, a genetic risk score was constructed for each case. The cumulative risk of IS events in the case group was presented using a cumulative incidence curve. All cases were followed up for 3 months, and functional outcomes were recorded prospectively.

\section{Results}

Two SNPs (rs4685423 and rs4618210) were significantly related to the risk of IS in MetS patients. For rs4685423, patients who were AA homozygotes were less likely to suffer from IS than C-allele carriers (OR $0.718 ; 95 \% \mathrm{Cl} 0.567-0.909 ;$ multivariate-adjusted, $P=0.006)$. For rs 4618210 , A-allele carriers were less likely to develop IS than patients who were GG homozygotes (OR 0.679; $95 \% \mathrm{Cl} 0.548-0.841$; multivariate-adjusted, $P<0.001)$. As the genetic risk score increased, the mean age at IS onset decreased (log-rank $P=0.010)$. There was no statistically significant difference in the distribution of the 90-day modified Rankin Scale (mRS) outcomes across the rs4685423 ( $P=0.319)$ or rs4618210 polymorphisms $(P=0.148)$.

\section{Conclusions}

Our findings suggested that genetic polymorphisms of PLCL2 might be associated with the onset of MetS-related IS. Further studies are warranted to validate our findings in other ethnic populations.

\section{Introduction}

Metabolic syndrome (MetS) encompasses a group of interrelated metabolic, physiological, biochemical and clinical factors, including hypertension, dyslipidaemia, insulin resistance, glucose intolerance and 
hyperglycaemia [1]. These factors accelerate the onset of stroke, type 2 diabetes mellitus, cardiovascular disease, and certain cancers [2-3]. As a complex condition, the development of MetS depends on genetic and environmental (e.g., lifestyle and sex) factors [4-6].

Stroke is a complex disease, and multiple genes interact with environmental risk factors, increasing the risk [7-8]. As the predominant type of stroke, ischaemic stroke (IS) has a multifactorial pathogenesis, with an estimated heritability of approximately $40 \%$ [8-9]. However, identification of the underlying genes has proven challenging. Genome-wide association studys (GWAS) have been remarkably successful in identifying loci that contribute to such complex diseases. More than 1 million single nucleotide polymorphisms (SNPs) spanning the whole genome can be genotyped with microarrays in a single GWAS [10-11].

A previous GWAS reported that in the PLCL2 gene, rs4618210 was associated with myocardial infarction [12]. Furthermore, in our earlier case-control study, we discovered a significant relationship between rs4618210 and rs4685423 and susceptibility to large artery atherosclerotic stroke [13]. Because atherosclerosis is the most common pathological change in stroke and myocardial infarction, we hypothesized that associations between PLCL2 gene polymorphisms and IS may exist in MetS patients. Therefore, based on previous GWASs, we used a fine-mapping strategy to determine the relationship between PLCL2 gene polymorphisms and the onset and short-term functional outcome of IS in MetS patients in a Chinese Han population in this investigation. Considering that age is a major risk factor in IS development, we analysed the effects of the variants in PLCL2 on the mean age of IS onset.

\section{Materials And Methods}

\subsection{Study Subjects}

Cases were identified from the Wenzhou Stroke Registry Programme (WSRP) between April 2014 and December 2018. The details of the WSRP have been described previously [14]. The patients were enrolled if they (1) were of Chinese Han nationality; (2) had their first-ever IS and were hospitalized within 7 days; (3) were diagnosed with MetS; and (4) were older than 18 years.

To reduce the influence of sex and age, the cases and the controls were matched for age and sex using pair matching. The age of the controls was increased or decreased within a 2-year range compared with the age of the cases. Controls were local residents who underwent physical examinations in hospitals. For the controls, inclusion criteria included (1) Chinese Han nationality; (2) a diagnosis of MetS; (3) no history of stroke or cardiovascular diseases; and (4) age over 18 years.

By asking for medical history or inquiring about the patient's previous written medical record, subjects with autoimmune and inflammatory disorders, severe heart, kidney, or liver dysfunction or malignancies were excluded from this study. Severe heart dysfunction was defined as grade III or grade IV cardiac function [15], severe kidney dysfunction was defined as stage III to stage V glomerular filtration rate [16] and severe liver dysfunction was defined as grade B or grade $C$ liver function [17]. 


\subsection{MetS Definition}

MetS was defined according to the revised criteria of the AHA/NHLBI statement [18]. The data on waist circumference were not available in the current investigation; thus, BMI $\geq 25$ was adopted as a proxy for central obesity [19]. When $\geq 3$ of the following criteria were met in a subject, MetS was diagnosed: (1) $\mathrm{BMI} \geq 25$; (2) blood pressure $\geq 130 / 85 \mathrm{mmHg}$ or antihypertensive medication use; (3) triglyceride level $\geq$ $1.70 \mathrm{mmol} / \mathrm{L}$ or lipid-lowering medication use; (4) high-density lipoprotein cholesterol level $<1.03 \mathrm{mmol} / \mathrm{L}$ in men and $<1.30 \mathrm{mmol} / \mathrm{L}$ in women or medication use; and (5) fasting plasma glucose level $\geq 5.6$ $\mathrm{mmol} / \mathrm{L}$ or antidiabetic medication use.

\subsection{Isolation of DNA and Genotyping}

Genomic DNA was extracted from peripheral blood with a Magen DNA isolation Kit (China). Improved multiplex ligation detection reaction (iMLDR) technology was adopted for genotyping PLCL2 gene polymorphisms [13]. For quality control, approximately $10 \%$ of samples were randomly subjected to repeated genotyping, resulting in 100\% concordance. Shanghai Genesky Biotechnology Company (Center for Human Genetics Research) supported the entire experimental course according to standard experimental procedures.

\subsection{Fine-mapping Strategy}

A fine-mapping strategy was used to identify the tagging SNPs (tSNPs). Briefly, we usd HapMap release 27 of merged phase III (http://www.hapmap.org) to identify a linkage disequilibrium (LD) block of 157.5 $\mathrm{kb}$ in the PLCL2 gene (chr3: 16949 586..17 107 089) in Han Chinese individuals and then used Haploview software (version 4.2; USA) to analyse the fine-mapping of the tSNPs based on their possibility of tagging the surrounding variants. For the selected SNPs, the inclusion criteria were as follows: (1) a minor allele frequency (MAF) $>0.05$, (2) a $P$-value for Hardy-Weinberg equilibrium (HWE) test $>0.05$, (3) linkage disequilibrium as assessed by $r^{2} \geq 0.8$, and (4) overall rate of genotyping $\geq 75 \%$. Based on the previous study, rs4618210 was also included [12]. As a result, a total of 8 SNPs were selected for this study (Supplementary Table 1).

\subsection{Follow-up and Outcome}

After the index stroke, the cases were prospectively followed up for 3 months via telephone interview or clinical visit. Follow-up was performed by trained physicians who were blinded to the baseline data. The modified Rankin Scale (mRS) was used to assess the functional outcome, and the mRS score at 3 months after stroke onset was tracked.

\subsection{Statistical Analysis}

Baseline characteristics and clinical features were compared between the cases and controls. The chisquare test was used to analyse the distributions of enumeration data, and the independent samples $t$ test was used to assess measurement data with a normal distribution. HWE was used to evaluate the 
genotypic distributions of the SNPs in the controls. The values of the selected SNPs for indicating the risk of IS were evaluated using logistic regression between the cases and the controls. The variables adjusted for included sex, age, hypertension, dyslipidaemia, hyperglycaemia, smoking and drinking. In logistic regression analysis, all the selected SNPs were assessed by three genetic models: a co-dominant model, a dominant model and a recessive model. Bonferroni correction was performed to control the false positive error rate in the multiple comparisons, and a $P$-value $<0.05 / 24(0.002)$ was deemed to be statistically significant. Power and Sample Size Program version 3.1.2 was used to estimate the power analyses. Because humans are diploid, the sample size (allele) was doubled in both the case and control groups. A type I error probability of 0.05 was used to estimate the power. One-way ANOVA was conducted to assess the mean age of IS onset for the variants of the selected SNPS. To analyse the mean age of IS onset among different risk score groups, a genetic risk score was constructed for each IS patient. The cumulative risk of IS events according to the variants of the selected SNPs in the cases is presented with a cumulative incidence curve, and comparisons were performed using the log-rank test. Event-free survival time was defined as the time from birth until first-ever IS. All analyses were performed by IBM SPSS Statistics (Version 20.0; IBM Corporation, USA) and two-sided values of $P<0.05$ were deemed statistically significant.

\section{Results}

\subsection{Baseline Characteristics and Clinical Features of the Study Subjects}

In the present study, 2 patients refused to provide blood samples. Finally, a total of 709 eligible patients with IS plus MetS and 711 eligible patients with MetS only were recruited in the current investigation. The baseline characteristics and clinical features of the participants are summarized in Table 1. The cases and controls were comparable in both age $(P=0.909)$ and sex $(P=0.917)$. The cases had a higher prevalence of dyslipidaemia $(P=0.002)$ and hypertension $(P=0.001)$ than the controls. Furthermore, the admission systolic blood pressure $(P=0.020)$, diastolic blood pressure $(P=0.003)$ and fasting glucose level $(P=0.009)$ were much higher in the cases than in the controls.

\subsection{PLCL2 Genetic Variation and its Association with IS in MetS Patients}

Table 2 shows the effect of PLCL2 genetic variation on the risk of IS in MetS patients. In the crude model, 2 SNPs (rs4685423 and rs4618210) were found to be significantly related to the risk of IS in MetS patients $(P<0.002)$ after Bonferroni correction. Regarding rs4685423, patients with the AA genotype were less likely to have IS than patients with the CC or CA genotype (recessive model, OR $0.684 ; 95 \% \mathrm{Cl} 0.546-$ $0.856 ; P=0.001)$. Regarding rs 4618210 , patients with the AA or GA genotype were less likely to suffer from IS than patients with the GG genotype (dominant model, OR $0.641 ; 95 \% \mathrm{Cl} 0.519-0.791 ; P<0.001$ ). In the multivariate model, after adjusting for potential confounders, rs 4685423 (recessive model, multivariate-adjusted, $P=0.006$ ) and rs4618210 (dominant model, multivariate-adjusted, $P<0.001$ ) were still significantly associated with the risk of IS in MetS patients. 
In the power analyses, the ORs for rs 4685423 and rs 4618210 were 0.759 and 0.727 , respectively. Based on the sample size, the statistical power of the present study achieved $95.30 \%$ and $98.10 \%$ for rs 4685423 and rs4618210, respectively.

\subsection{Effects of the Two Variants in PLCL2 on the Mean Age of IS Onset}

We evaluated whether the rs 4685423 and rs 4618210 polymorphisms affected the age of IS onset in the cases. For rs4685423, patients with the AA genotype had a much higher mean age of IS onset than patients with the $\mathrm{CC}$ or $\mathrm{CA}$ genotype $(P=0.003$, Fig. 1A). The mean ages of onset for the CC genotype, $\mathrm{CA}$ genotype and AA genotype were $63.61 \pm 10.84,65.15 \pm 11.16$ and $67.65 \pm 11.82$, respectively $(P=0.003$, Table 3). The rs 4685423 polymorphism was significantly related to the mean age of IS onset (log-rank $P$ $<0.001$, Fig. 1B). The mean ages of onset for the GG, GA and AA genotypes in rs4618210 were $65.06 \pm$ $11.50,65.33 \pm 11.13$ and $68.02 \pm 11.27$, respectively $(P=0.079$, Fig. 1 C, Table 3$)$. No association was found between the rs4618210 polymorphism and age of stroke onset (log-rank $P=0.113$, Fig. 1D).

Because of the potential interactions of the PLCL2 variants with age at onset, we combined the rs4685423 and rs4618210 polymorphisms according to the number

of risk genotypes (i.e., rs4685423 CC/CA and rs4618210 GG). As a result, the mean age was $69.16 \pm$ 11.45 years for those with no risk genotype (rs4685423 AA and rs4618210 GA/AA), $65.70 \pm 11.25$ years for those with one risk genotype (rs4685423 CC/CA or rs4618210 GG), and $64.24 \pm 11.31$ years for those with two risk genotypes (rs4685423 CC/CA and rs4618210 GG) ( $P=0.006$; Fig. 2A and Table 3). The mean age at IS onset decreased with increasing genetic risk score (log-rank $P=0.010$, Fig. 2B).

\subsection{Association Between the Two Variants in PLCL2 and 3-month Functional Outcome}

After a 3-month follow-up, 9 IS patients with MetS were lost to follow-up. The remaining 700 IS patients with MetS were analysed for the relationship between the rs 4685423 and rs4618210 polymorphisms and 3-month functional outcome.

The mRS scores at 3 months in IS patients with MetS across the rs4685423 and rs4618210 polymorphisms are presented in Fig. 3. There was no statistically significant difference in the distribution of the mRS scores across the rs4685423 (Fig. 3A, $P=0.319$ ) or rs4618210 (Fig. 3B, $P=0.148$ ) polymorphisms.

\section{Discussion}

In this study, we investigated the relationship of the polymorphisms of the PLCL2 gene with the onset and short-term prognosis of IS with MetS. The results showed that MetS patients with the rs4685423 AA genotype and the rs 4618210 AA/GA genotype had a decreased risk of IS. Notably, the rs4685423 AA genotype was significantly correlated with later age of IS onset. As the genetic risk score increased, the mean age of IS onset decreased. These findings provide insights into the genetic basis of MetS-related IS and suggest a novel therapeutic approach that may be applicable for future stroke prevention. 
MetS is a rapidly progressing global socioeconomic problem because of increasing obesity and age [2021]. It is related to endothelial dysfunction and a pro-inflammatory state that places subjects at a high risk of atherosclerosis. Moreover, data from previous studies showed that MetS elevated the risk of stroke, cardiovascular disease, stroke recurrence, and all-cause mortality [22-24].

As the most common pathological process, atherosclerosis leads to MetS-related IS and cardiovascular diseases. Atherosclerotic plaques are formed of necrotic cores, accumulated modified lipids, calcified regions, leukocytes, inflamed smooth muscle cells, foam and endothelial cells [25]. These abovementioned features indicate that the immune system and many components of the vascular and metabolic systems are involved in the atherosclerosis process [26].

Phospholipase C (PLC) proteins are significant intercessors of the calcium-protein kinase $C$ signalling pathway. PLCL2, a novel catalytically inactive PLC-like protein, is expressed in haematopoietic cells. The PLCL2 gene is located on chromosome 3p24.3 and has been identified as a novel susceptibility site for myocardial infarction in Japanese populations [12]. Experimental data showed [27] that 1) in PLCL2deficient mice, mature B cells were hyperproliferative in response to B-cell receptor cross-linking and had a more intense T-cell-independent antigen reaction and that 2) in PLCL2-deficient B cells, calcium influx accumulation in nuclei was increased, and extracellular signal-regulated kinase movement was reinforced. All these data indicated that PLCL2 is a passive regulator of immune responses and B-cell receptor signalling. Mature B cells undergo FAS-reconciled apoptosis [28], and PLCL2 expression is indirectly affected by FAS [29]. Thus, we speculate that rs 4685423 and rs 4618210 may be directly or indirectly associated with the serum level of PLCL2, which is not only related to the management of B-cell maturation, resulting in the formation of atherosclerotic lesions, but also associated with IS in MetS patients. Our speculation is consistent with that of GeneCards (http://www.genecards.org), which supports that $P L C L 2$ plays a key role in the pathogenesis of atherosclerosis.

In the current study, patients with the rs4685423 AA genotype had a much higher mean age of IS onset than patients with the CC or CA genotype. Furthermore, as the genetic risk score increased, the age of IS onset decreased. The mechanism underlying the associations is unclear, and further investigations are required to determine the effect of this mutation and its connected effects with other mutations on age at IS onset.

The limitation of this investigation is that waist circumference data were not available and we used BMI instead. However, an earlier study reported that both waist circumference and BMI can be used for the prediction of central obesity in Chinese adults [30]. In addition, the serum level of PLCL2 was not tested. Hence, we did not assess the relationship between different genotypes of rs4685423 and rs4618210 and the serum levels of PLCL2, which restricted our analyses. Moreover, the signalling pathway and the function of PLCL2 in atherosclerosis remain largely unknown. Thus, molecular and cellular experiments should be designed to further elucidate the mechanism involved.

In summary, our findings imply that rs4618210 and rs4685423 of the PLCL2 gene might contribute to the development of IS in MetS patients. Subsequent investigations are needed to verify whether the PLCL2 
gene can be a target for a novel therapeutic way to prevent stroke.

\section{Declarations}

\section{Author contributions section}

Xiaoya Huang, Qiang Ye, Jun Sun and Zusen Ye designed the study.

Xiaoya Huang, Qiang Ye, Yanlei Zhang, Yanyan Chen and Yanlei Zhang performed the experiment.

Xiaoya Huang, Qiang Ye, Jun Sun and Zusen Ye analysed the data.

Xiaoya Huang, Yanlei Zhang, and Zusen Ye wrote the manuscript.

Yanyan Chen and Jia Li prepared the figure.

Yanyan Chen and Jia Li edited the manuscript.

Xiaoya Huang, Jia Li and Zusen Ye provided financial support.

\section{Funding statement}

This study was supported by Zhejiang Provincial Natural Science Foundation - China (LY17H090016, LQ17H090001), Zhejiang Provincial Medical and Health Science Technology Project - China (2020RC033, 2018KY122) and Wenzhou Science \& Technology Bureau (Y20190131, Y20180135, Y20170335).

\section{Availability of data and material}

All data and material in the present study are available.

\section{Compliance with ethical standards}

Ethics Statement

Two hospitals (The First Affiliated Hospital of Wenzhou Medical University and Wenzhou Central Hospital) in China participated in the study. The institutional review board of the participating hospitals approved all study documents and procedures. Informed consent was provided by participants or by relatives as legally required, in accordance with the guidelines of the Helsinki Declaration.

Conflict of interest

The authors declare no conflict of interest.

Consent to participate 
All participants volunteered to participate in the present study.

\section{Consent for publication}

We submit our manuscript entitled "Fine-mapping of the PLCL2 gene identifies candidate variants associated with ischaemic stroke risk in metabolic syndrome patients" to Molecular Neurobiology for publication.

\section{References}

1. Rani V, Deep G, Singh RK, Palle K, Yadav UC (2016) Oxidative stress and metabolic disorders: Pathogenesis and therapeutic strategies. Life Sci 148:183-193

2. Pothiwala P, Jain SK, Yaturu S (2009) Metabolic syndrome and cancer. Metab Syndr Relat Disord 7:279-288

3. Lent-Schochet D, McLaughlin M, Ramakrishnan N, Jialal I (2019) Exploratory metabolomics of metabolic syndrome: A status report. World J Diabetes 10:23-36

4. Pollex RL, Hegele RA (2006) Genetic determinants of the metabolic syndrome. Nat Clin Pract Cardiovasc Med 3:482-489

5. Edwardson CL, Gorely T, Davies MJ et al (2012) Association of sedentary behaviour with metabolic syndrome: a meta-analysis. PLoS One 7:e34916

6. Malik VS, Popkin BM, Bray GA, Després JP, Willett WC, Hu FB (2010) Sugar-sweetened beverages and risk of metabolic syndrome and type 2 diabetes: a meta-analysis. Diabetes Care 33:2477-2483

7. Flossmann E, Schulz UG, Rothwell PM (2004) Systematic review of methods and results of studies of the genetic epidemiology of ischemic stroke. Stroke 35:212-227

8. Bevan S, Traylor M, Adib-Samii P et al (2012) Genetic heritability of ischemic stroke and the contribution of previously reported candidate gene and genomewide associations. Stroke 43:31613167

9. Holliday EG, Maguire JM, Evans TJ et al (2012) Common variants at 6p21.1 are associated with large artery atherosclerotic stroke. Nat Genet 44:1147-1151

10. Markus HS (2013) WellcomeTrust genome-wide association study of ischemic stroke. Stroke 44:S20S22

11. Meschia JF, Arnett DK, Ay H et al (2013) Stroke Genetics Network (SiGN) study: design and rationale for a genome-wide association study of ischemic stroke subtypes. Stroke 44:2694-2702

12. Hirokawa M, Morita H, Tajima T et al (2015) A genome-wide association study identifies PLCL2 and AP3D1-D0T1L-SF3A2 as new susceptibility loci for myocardial infarction in Japanese. Eur J Hum Genet 23:374-380

13. Huang X, Zhu Z, Chen Y et al (2020) Two Novel SNPs in the PLCL2 Gene Associated with Large Artery Atherosclerotic Stroke Identified by Fine-Mapping. J Mol Neurosci 70:496-503 
14. Ye Z, Huang X, Han Z et al (2015) Three-year prognosis of first-ever primary pontine hemorrhage in a hospital-based registry. J Clin Neurosci 22:1133-1138

15. White PD, Myers MM (1921) The classification of cardiac diagnosis. JAMA 77:1414-1415

16. National Kidney Foundation (NKF) K/DOQI Guidelines (2003) K/DOQI clinical practice guidelines for bone metabolism and disease in chronic kidney disease. Am J Kidney Dis 42:S1-S201

17. Anthony PP, Ishak KG, Nayak NC et al (1977) The morphology of cirrhosis: definition, nomenclature, and classification. Bull World Health Organ 55:521-540

18. Grundy SM, Cleeman JI, Daniels SR et al (2005) Diagnosis and management of the metabolic syndrome: an American Heart Association/National Heart, Lung, and Blood Institute Scientific Statement. Circulation 112:2735-2752

19. Examination Committee of Criteria for 'Obesity Disease' in Japan; Japan Society for the Study of Obesity (2002) New criteria for 'obesity disease' in Japan. Circ J 66:987-992

20. Aguilar M, Bhuket T, Torres S, Liu B, Wong RJ (2015) Prevalence of the metabolic syndrome in the United States, 2003-2012. JAMA 313:1973-1974

21. O'Neill S, O'Driscoll L (2015) Metabolic syndrome: a closer look at the growing epidemic and its associated pathologies. Obes Rev 16:1-12

22. Mottillo S, Filion KB, Genest J et al (2010) The metabolic syndrome and cardiovascular risk a systematic review and meta-analysis. J Am Coll Cardiol 56:1113-1132

23. Rodriguez-Colon SM, Mo J, Duan Y et al (2009) Metabolic syndrome clusters and the risk of incident stroke: the atherosclerosis risk in communities (ARIC) study. Stroke 40:200-205

24. Liou CW, Tan TY, Lin TK, Wang PW, Yip HK (2008) Metabolic syndrome and three of its components as risk factors for recurrent ischaemic stroke presenting as large-vessel infarction. Eur $\mathrm{J}$ Neurol 15:802-809

25. Naghavi M, Libby P, Falk E et al (2003) From vulnerable plaque to vulnerable patient: a call for new definitions and risk assessment strategies: Part I. Circulation 108:1664-1672

26. Galkina E, Ley K (2009) Immune and inflammatory mechanisms of atherosclerosis $\left(^{*}\right)$. Annu Rev Immunol 27:165-197

27. Takenaka K, Fukami K, Otsuki M et al (2003) Role of phospholipase C-L2, a novel phospholipase Clike protein that lacks lipase activity, in B-cell receptor signaling. Mol Cell Biol 23:7329-7338

28. Fukuyama H, Adachi M, Suematsu $S$ et al (2002) Requirement of Fas expression in B cells for tolerance induction. Eur J Immunol 32:223-230

29. Kobayashi SD, Voyich JM, Braughton KR, DeLeo FR (2003) Down-regulation of proinflammatory capacity during apoptosis in human polymorphonuclear leukocytes. J Immunol 170:3357-3368

30. Ovbiagele B, Saver JL, Lynn MJ, Chimowitz M, WASID Study Group (2006) Impact of metabolic syndrome on prognosis of symptomatic intracranial atherostenosis. Neurology 66:1344-1349

\section{Tables}


Table 1 Baseline characteristics of participants.

\begin{tabular}{|lllll|}
\hline Characteristic & $\begin{array}{l}\text { IS plus MetS }(\mathrm{n}= \\
709)\end{array}$ & $\begin{array}{l}\text { MetS alone }(\mathrm{n}= \\
711)\end{array}$ & $\begin{array}{l}\text { Chi-square or } t \\
\text { test }\end{array}$ & $\begin{array}{l}P \\
\text { value }\end{array}$ \\
\hline Age $\geq 65$ years, $\mathrm{n}(\%)$ & $403(56.84)$ & $402(56.54)$ & 0.013 & 0.909 \\
\hline Male, $\mathrm{n}(\%)$ & $365(51.48)$ & $368(51.76)$ & 0.011 & 0.917 \\
\hline Hypertension, $\mathrm{n}(\%)$ & $515(72.64)$ & $457(64.28)$ & 11.494 & $0.001^{*}$ \\
\hline Hyperglycaemia, $\mathrm{n}(\%)$ & $308(43.44)$ & $288(40.51)$ & 1.256 & 0.262 \\
\hline Dyslipidaemia, $\mathrm{n}(\%)$ & $295(41.61)$ & $240(33.76)$ & 9.323 & $0.002^{*}$ \\
\hline Smoking, $\mathrm{n}(\%)$ & $242(34.13)$ & $229(32.21)$ & 0.593 & 0.441 \\
\hline Drinking, $\mathrm{n}(\%)$ & $229(32.29)$ & $221(31.08)$ & 0.242 & 0.622 \\
\hline BMI, $\left(\mathrm{kg} / \mathrm{m}^{2}\right)$ & $25.22 \pm 2.09$ & $25.29 \pm 2.05$ & 0.683 & 0.495 \\
\hline $\begin{array}{l}\text { Fasting glucose, } \\
\text { (mmol/L) }\end{array}$ & $7.19 \pm 3.27$ & $6.79 \pm 2.45$ & 2.603 & $0.009^{*}$ \\
\hline SBP, $(\mathrm{mm} \mathrm{Hg})$ & $142.82 \pm 18.64$ & $140.56 \pm 17.92$ & 2.325 & $0.020^{*}$ \\
\hline DBP, $(\mathrm{mm} \mathrm{Hg})$ & $81.62 \pm 11.76$ & $79.83 \pm 10.76$ & 2.998 & $0.003^{*}$ \\
\hline Triglyceride, (mmol/L) & $1.98 \pm 1.04$ & $1.99 \pm 0.95$ & 0.246 & 0.806 \\
\hline HDL-C, $(\mathrm{mmol} / \mathrm{L})$ & $1.13 \pm 0.40$ & $1.11 \pm 0.36$ & 1.139 & 0.255 \\
\hline
\end{tabular}

Abbreviations: IS = ischaemic stroke; MetS = metabolic syndrome; $\mathrm{BMI}=$ body mass index; SBP = systolic blood pressure; $\mathrm{DBP}$ = diastolic blood pressure; $\mathrm{HDL}-\mathrm{C}=$ high-density lipoprotein cholesterol.

${ }^{*} P$ value $<0.05$ was considered statistically significant.

Table 2 Association between PLCL2 and risk of IS plus MetS. 


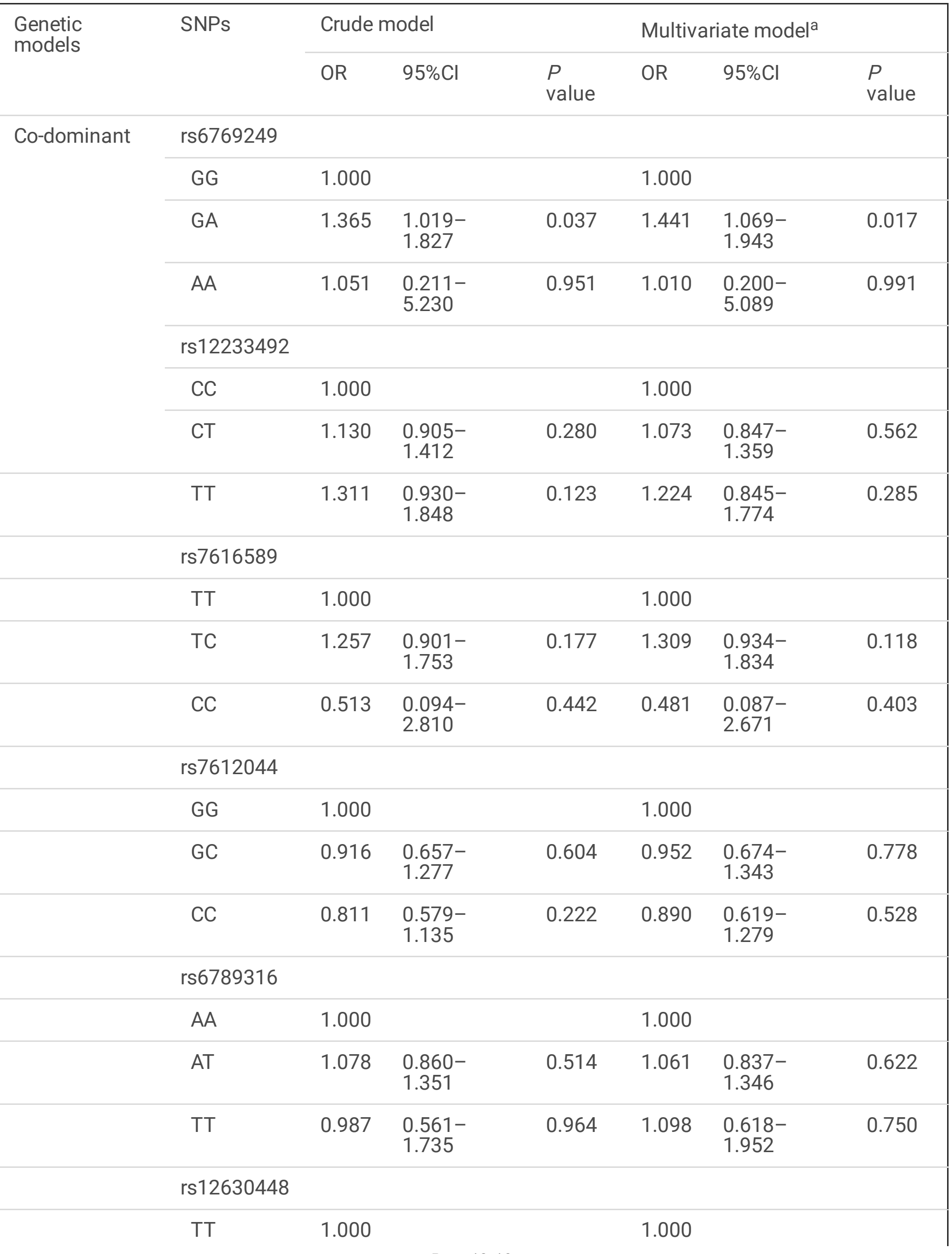




\begin{tabular}{|c|c|c|c|c|c|c|c|}
\hline & TG & 0.759 & $\begin{array}{l}0.595- \\
0.966\end{array}$ & 0.025 & 0.727 & $\begin{array}{l}0.567- \\
0.932\end{array}$ & 0.012 \\
\hline & $\mathrm{GG}$ & 1.102 & $\begin{array}{l}0.623- \\
1.948\end{array}$ & 0.738 & 1.107 & $\begin{array}{l}0.618- \\
1.982\end{array}$ & 0.733 \\
\hline \multicolumn{8}{|c|}{ rs4685423 } \\
\hline & CC & 1.000 & & & 1.000 & & \\
\hline & CA & 0.780 & $\begin{array}{l}0.582- \\
1.044\end{array}$ & 0.095 & 0.794 & $\begin{array}{l}0.590- \\
1.070\end{array}$ & 0.130 \\
\hline & AA & 0.568 & $\begin{array}{l}0.415- \\
0.777\end{array}$ & $<.001$ & 0.601 & $\begin{array}{l}0.432- \\
0.836\end{array}$ & 0.003 \\
\hline \multicolumn{8}{|c|}{ rs4618210 } \\
\hline & GG & 1.000 & & & 1.000 & & \\
\hline & GA & 0.650 & $\begin{array}{l}0.518- \\
0.815\end{array}$ & $\begin{array}{l}< \\
0.001\end{array}$ & 0.672 & $\begin{array}{l}0.534- \\
0.845\end{array}$ & 0.001 \\
\hline & AA & 0.615 & $\begin{array}{l}0.449- \\
0.844\end{array}$ & 0.003 & 0.700 & $\begin{array}{l}0.507- \\
0.968\end{array}$ & 0.031 \\
\hline \multirow[t]{8}{*}{ Dominant } & rs6769249 & 1.355 & $\begin{array}{l}1.015- \\
1.808\end{array}$ & 0.039 & 1.426 & $\begin{array}{l}1.062- \\
1.916\end{array}$ & 0.018 \\
\hline & rs12233492 & 1.165 & $\begin{array}{l}0.943- \\
1.439\end{array}$ & 0.158 & 1.097 & $\begin{array}{l}0.872- \\
1.379\end{array}$ & 0.430 \\
\hline & rs7616589 & 1.217 & $\begin{array}{l}0.878- \\
1.687\end{array}$ & 0.238 & 1.262 & $\begin{array}{l}0.906- \\
1.758\end{array}$ & 0.169 \\
\hline & rs7612044 & 0.865 & $\begin{array}{l}0.631- \\
1.185\end{array}$ & 0.366 & 0.928 & $\begin{array}{l}0.665- \\
1.293\end{array}$ & 0.658 \\
\hline & rs6789316 & 1.068 & $\begin{array}{l}0.859- \\
1.328\end{array}$ & 0.552 & 1.066 & $\begin{array}{l}0.849- \\
1.338\end{array}$ & 0.585 \\
\hline & rs12630448 & 0.794 & $\begin{array}{l}0.631- \\
1.000\end{array}$ & 0.050 & 0.765 & $\begin{array}{l}0.603- \\
0.970\end{array}$ & 0.027 \\
\hline & rs4685423 & 0.690 & $\begin{array}{l}0.523- \\
0.911\end{array}$ & 0.009 & 0.724 & $\begin{array}{l}0.543- \\
0.964\end{array}$ & 0.027 \\
\hline & rs4618210 & 0.641 & $\begin{array}{l}0.519- \\
0.791\end{array}$ & $\begin{array}{l}< \\
0.001\end{array}$ & 0.679 & $\begin{array}{l}0.548- \\
0.841\end{array}$ & $\hat{L}_{0.001}$ \\
\hline \multirow[t]{3}{*}{ Recessive } & rs6769249 & 1.003 & $\begin{array}{l}0.202- \\
4.985\end{array}$ & 0.997 & 0.961 & $\begin{array}{l}0.191- \\
4.841\end{array}$ & 0.961 \\
\hline & rs12233492 & 1.228 & $\begin{array}{l}0.889- \\
1.695\end{array}$ & 0.212 & 1.171 & $\begin{array}{l}0.834- \\
1.644\end{array}$ & 0.362 \\
\hline & rs7616589 & 0.500 & $\begin{array}{l}0.091- \\
2.739\end{array}$ & 0.424 & 0.466 & $\begin{array}{l}0.084- \\
2.587\end{array}$ & 0.383 \\
\hline
\end{tabular}




\begin{tabular}{|c|c|c|c|c|c|c|}
\hline rs7612044 & 0.869 & $\begin{array}{l}0.703- \\
1.073\end{array}$ & 0.193 & 0.927 & $\begin{array}{l}0.738- \\
1.163\end{array}$ & 0.511 \\
\hline rs6789316 & 0.963 & $\begin{array}{l}0.551- \\
1.684\end{array}$ & 0.895 & 1.080 & $\begin{array}{l}0.610- \\
1.912\end{array}$ & 0.793 \\
\hline rs12630448 & 1.184 & $\begin{array}{l}0.672- \\
2.086\end{array}$ & 0.558 & 1.213 & $\begin{array}{l}0.681- \\
2.162\end{array}$ & 0.513 \\
\hline rs4685423 & 0.684 & $\begin{array}{l}0.546- \\
0.856\end{array}$ & 0.001 & 0.718 & $\begin{array}{l}0.567- \\
0.909\end{array}$ & 0.006 \\
\hline rs4618210 & 0.755 & $\begin{array}{l}0.561- \\
1.016\end{array}$ & 0.064 & 0.847 & $\begin{array}{l}0.625- \\
1.149\end{array}$ & 0.287 \\
\hline
\end{tabular}

Abbreviations: IS = ischaemic stroke; MetS = metabolic syndrome; SNP = single nucleotide polymorphism; $\mathrm{OR}=$ odds ratio; $\mathrm{Cl}$ = confidence interval.

${ }^{\text {a } A d j u s t e d ~ f o r ~ a g e, ~ s e x, ~ h y p e r t e n s i o n, ~ h y p e r g l y c a e m i a, ~ d y s l i p i d a e m i a, ~ s m o k i n g ~ a n d ~ d r i n k i n g . ~}$

Table 3 Association between the rs 4685423 and rs 4618210 polymorphisms and genetic risk score with mean age at ischaemic stroke onset.

\begin{tabular}{|llllllll|}
\hline Variants & \multicolumn{2}{l}{$\begin{array}{l}\text { Mean age in different groups } \\
\text { (N/mean age) }\end{array}$} & \multicolumn{4}{l|}{$\begin{array}{l}\text { Comparison of mean age in different } \\
\text { groups }(P \text { value })\end{array}$} \\
\hline rs4685423 & CC & CA & AA & Overall & $\begin{array}{l}\text { CC vs. } \\
\text { CA }\end{array}$ & $\begin{array}{l}\text { CC vs. } \\
\text { AA }\end{array}$ & $\begin{array}{l}\text { CA vs. } \\
\text { AA }\end{array}$ \\
\cline { 2 - 8 } & $141 / 63.61$ & $371 / 65.15$ & $197 / 67.65$ & 0.003 & 0.169 & 0.001 & 0.012 \\
\hline rs4618210 & GG & GA & AA & Overall & $\begin{array}{l}\text { GG vs. } \\
\text { GA }\end{array}$ & $\begin{array}{l}\text { GG vs. } \\
\text { AA }\end{array}$ & GA vs. \\
\hline $\begin{array}{l}\text { Genetic risk } \\
\text { score }\end{array}$ & 0 & $261 / 65.33$ & $91 / 68.02$ & 0.079 & 0.773 & 0.026 & 0.051 \\
\hline
\end{tabular}

a The number represents the numbers of risk genotypes within the combined genotypes; the risk genotypes used for the calculation were rs 4685423 CC/CA and rs4618210 GG.

\section{Figures}



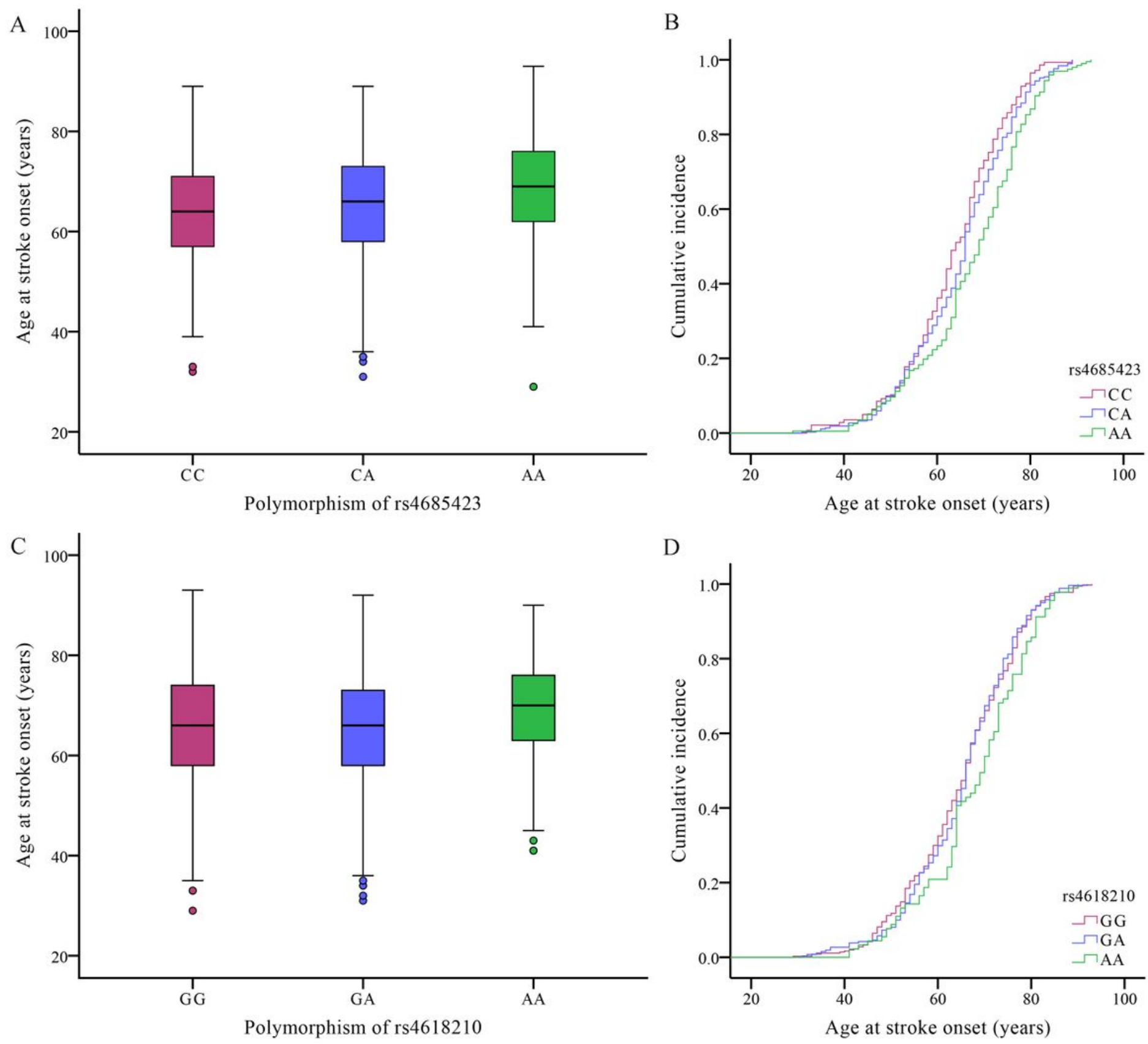

Figure 1

Effects of the polymorphisms of rs 4685423 and rs4618210 on the age of ischaemic stroke onset in the cases. (A) Box plot of age at onset among ischaemic stroke patients with the CC genotype, CA genotype and AA genotype in rs4685423 ( $P=0.003)$; (B) Cumulative incidence curve of ischaemic stroke patients with the polymorphisms of rs 4685423 (log-rank $\mathrm{P}<0.001$ ); (C) Box plot of age at onset among ischaemic stroke patients with the GG genotype, GA genotype and AA genotype in rs4618210 ( $P=0.079$ ); (D) Cumulative incidence curve of ischaemic stroke patients with the polymorphisms of rs 4618210 (log-rank $P=0.113)$. 

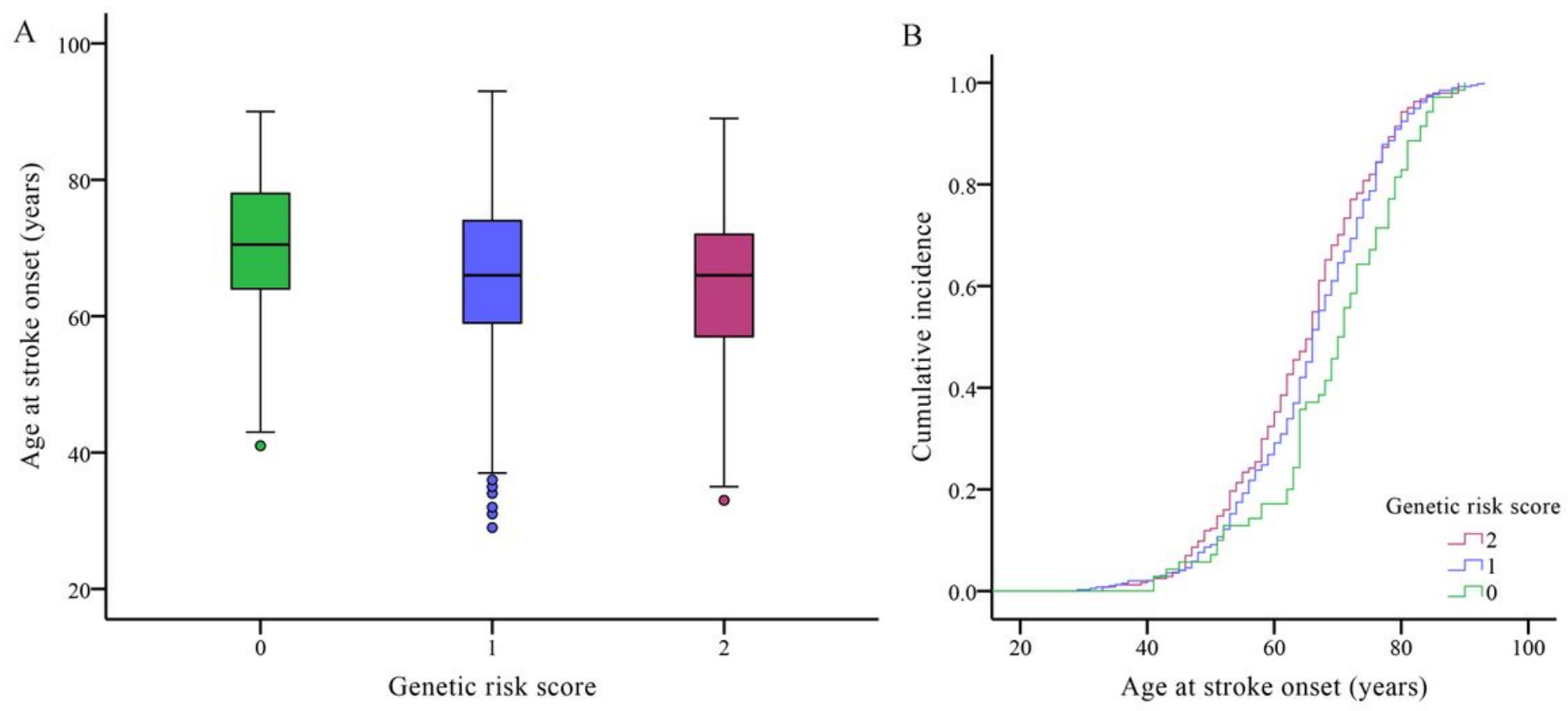

Figure 2

Effects of the genetic risk score on the age of ischaemic stroke onset. (A) Box plot of age at onset in three genetic risk score groups $(P=0.006)$. (B) Cumulative incidence curve of patients by genetic risk score (log-rank $P=0.010)$. 


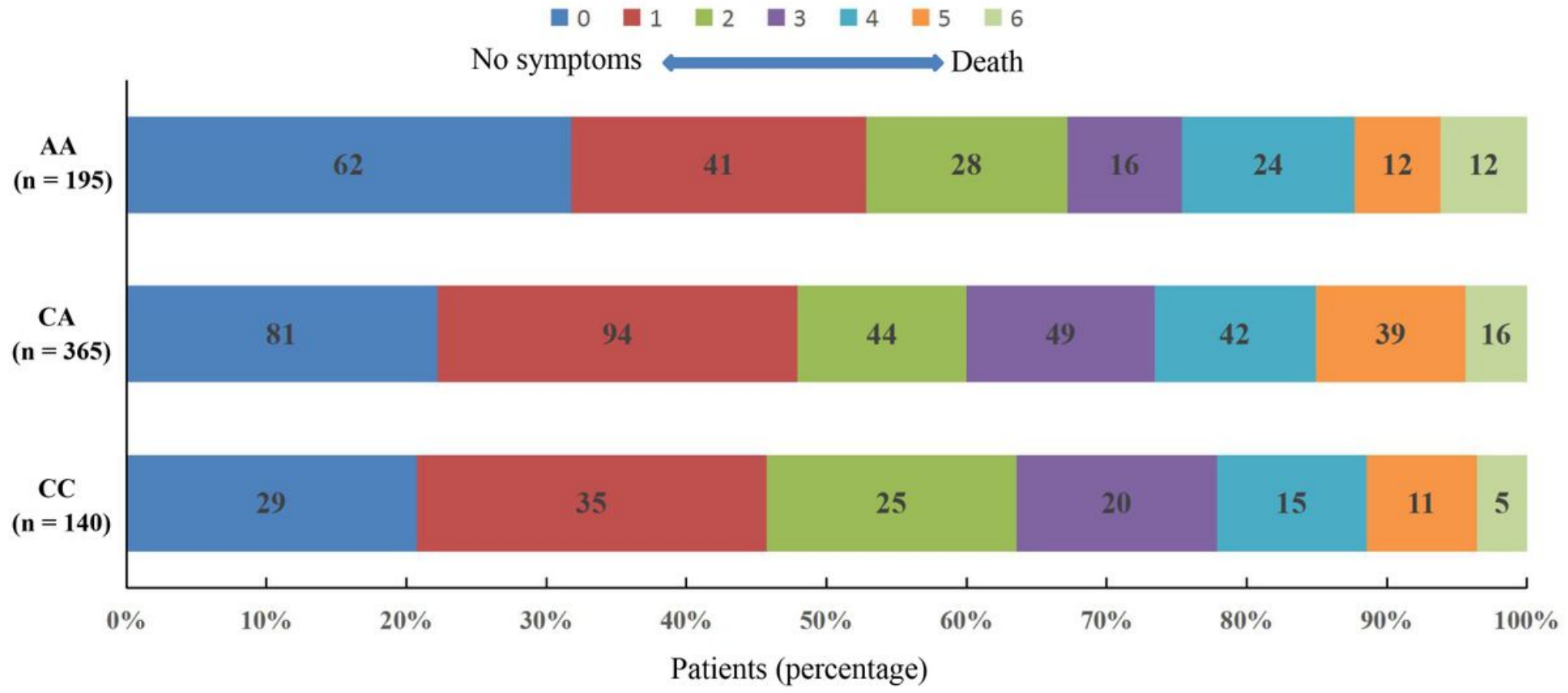

B

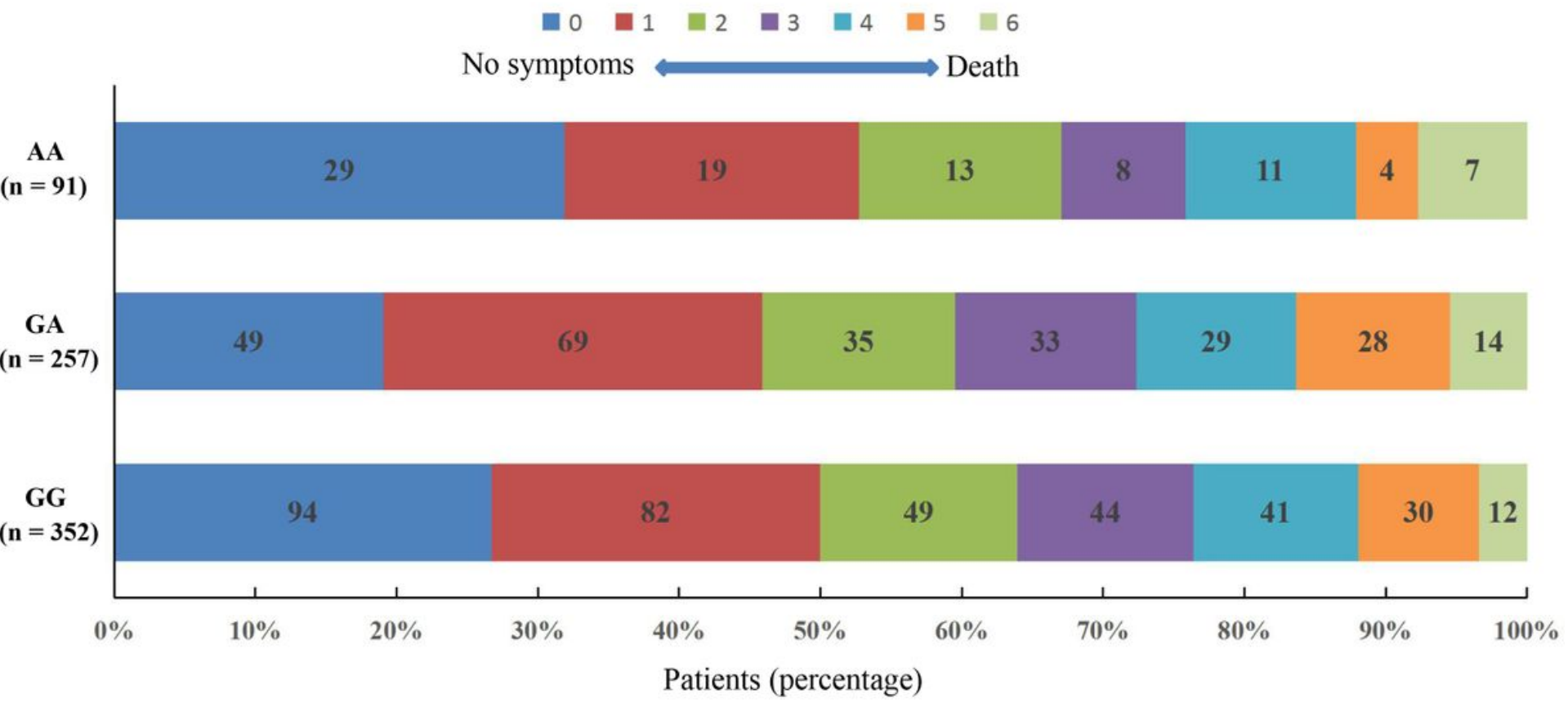

\section{Figure 3}

Scores on the modified Rankin Scale at 3 months in ischaemic stroke patients with metabolic syndrome across the polymorphisms of rs 4685423 and rs4618210. There was no significantly different shift in the distribution of the mRS scores across the polymorphisms of rs4685423 (Fig. $3 \mathrm{~A}, \mathrm{~F}=1.146, \mathrm{P}=0.319$ ) or rs4618210 (Fig. 3B, F = 1.919, $\mathrm{P}=0.148$ ).

\section{Supplementary Files}


This is a list of supplementary files associated with this preprint. Click to download.

- SupplementaryTable1.doc 